\title{
$\beta^{+}-\gamma$ 同時計測陽電子寿命測定法による SUS316 鋼の 非破壊的疲労評価
}

\author{
Prasert Chalermkarnnon ${ }^{1, * 1}$ \\ 河口恭寛 $2, * 2$ \\ 荒木秀 樹 1,3 \\ 白井泰 治 1,3
}

${ }^{1}$ 大阪大学大学院工学研究科マテリアル科学専攻

2株式会社 原子力安全システム研究所技術システム研究所

3 大阪大学大学院工学研究科フロンティア研究機構

J. Japan Inst. Metals, Vol. 66, No. 12 (2002), pp. 1293-1296

Special Issue on Materials and Technologies for Risk Society

(C) 2002 The Japan Institute of Metals

\section{Non-Destructive Evaluation of Fatigue Damage in Type 316 Stainless Steel by Using $\beta^{+}-\gamma$ Coincidence Positron Lifetime Spectrometer}

Prasert Chalermkarnnon ${ }^{1, * 1}$, Yasuhiro Kawaguchi²,*2, Hideki Araki ${ }^{1,3}$ and Yasuharu Shirai ${ }^{1,3}$

${ }^{1}$ Department of Materials Science and Engineering, Osaka University, Suita 565-0871

${ }^{2}$ Institute of Nuclear Technology, Institute of Nuclear Safety System, Inc., Mihama-cho 919-1205

${ }^{3}$ Frontier Research Center, Graduate School of Engineering, Osaka University, Suita 565-0871

\begin{abstract}
Newly developed $\beta^{+}-\gamma$ coincidence positron lifetime spectroscopy was applied to analysis of fatigue damage aiming at nondestructive evaluation of fatigue stored in type 316 stainless steel which is mostly used in primary water line of pressurized water reactor. Stress-controlled fatigue specimens and strain-controlled fatigue specimens were prepared and relations between fatigue life and positron lifetime were investigated. Mean positron lifetime increases with the fatigue life monotonically in both fatigue test modes. In the strain-controlled mode, mean positron lifetime increases faster at early stage than that in the stress-controlled mode; however, it converges to the same value at the end of the fatigue life in both conditions. Component analysis of positron lifetime spectra revealed that main defects are dislocations and their density increases with fatigue life to a critical value. With this non-destructive evaluation method, the fatigue damage can be analyzed precisely without destruction of the sample.
\end{abstract}

(Received June 24, 2002; Accepted September 30, 2002)

Keywords: fatigue, non-destructive evaluation, positron lifetime, positron-gamma coincidence, type 316 stainless steel

\section{1. 緒言}

原子力発電所の一次系配管等に多く用いられるステンレス 鋼 SUS316 について，蓄積される疲労による損傷度を非破 壊的に評価するため，新しく開発した $\beta^{+}-\gamma$ 陽電子寿命測定 法1をを適用した。疲労損傷については, 初期亀裂が発生する までの潜伏期間が長く，亀裂の進展は速い，そのため，潜伏 期間に打ける疲労の蓄積程度を把握することが重要となる。 陽電子消滅法 2,3$)$ は, 塑性変形による転位や空孔などのミク 口組織の変化に敏感であることから亀裂発生前の疲労蓄積程 度を非破壊的に評価するための手法として有望と考えられる.

消滅 $\gamma$ 線のドップラー幅広がり測定を用いた陽電子消滅法 によって, ステンレス鋼 SUS316 の非破壊的疲労損傷度評 価が可能であることは既に報告されている4). 相対変化量で 評価するドップラー幅広がり測定と違って，陽電子寿命測定 法は陽電子寿命の絶対值そのものが物理量であり，そのため

\footnotetext{
*1 大阪大学大学院生 (Graduate Student, Osaka University)

*2 現在 : 関西電力侏 (Present address: The Kansai Electric Power Co., Inc.)
}

材料中の格子欠陥の種類とその量が独立に評価できる．そこ で，ドップラー幅広がり測定より得られる情報量が多くかつ 精確である陽電子寿命測定を用いれば，疲労損傷度を非破壊 的に精度よくその場評価ができると考えられる。

従来の陽電子寿命測定 $(\gamma-\gamma$ 同時計測法)においては，通常 は 2 枚の試験片で陽電子線源をサンドイッチして密着させ る必要がある．その上 $\gamma$ 線検出器に 2 本の光電子増倍管が 必要であることから，現場で非破壊測定に用いることは極め て困難である。しかし，我々が新しく開発した $\beta^{+}-\gamma$ 陽電子 寿命測定法1)を用いれば，陽電子線源と試料を分離すること が可能となり，非破壊・非接触測定を実現することができる.

本研究では, $\beta^{+}-\gamma$ 陽電子寿命測定法によりステンレス鋼 SUS316 の疲労評価を行ない，さらにその測定装置を改良 し, 稼動中の機器の重要部材の損傷度評価を現場で精確に診 断することが可能な可搬型の非破壊材料評価装置の開発を試 みた。

\section{2. 実 験 方 法}

本実験で用いたステンレス鋼 SUS316 疲労試験材料の化 
Table 1 Chemical composition of type 316 stainless steel test specimen (mass\%).

\begin{tabular}{lcccccccccc}
\hline & $\mathrm{C}$ & $\mathrm{Si}$ & $\mathrm{Mn}$ & $\mathrm{P}$ & $\mathrm{S}$ & $\mathrm{Ni}$ & $\mathrm{Cr}$ & $\mathrm{Mo}$ & Solution heat treated & Base metal size $(\mathrm{mm})$ \\
\hline \multirow{2}{*}{ JIS } & MAX & MAX & MAX & MAX & MAX & 10.00 & 16.00 & 2.00 & \multirow{2}{*}{$1010^{\circ} \mathrm{C} / 1150^{\circ} \mathrm{C}$} & - \\
\hline \multirow{2}{*}{ Present work } & 0.08 & 1.00 & 2.00 & 0.045 & 0.030 & $/ 14.00$ & $/ 18.00$ & $/ 3.00$ & & - \\
\hline
\end{tabular}

Table 2 Mechanical properties of type 316 stainless steel test specimen.

\begin{tabular}{lccc}
\hline & $\begin{array}{c}\text { Yield stress } \\
(\mathrm{MPa})\end{array}$ & $\begin{array}{c}\text { Tensile stress } \\
(\mathrm{MPa})\end{array}$ & $\begin{array}{c}\text { Elongation } \\
(\%)\end{array}$ \\
\hline JIS & MIN 205 & MIN 520 & MIN 40 \\
\hline Present work & 284 & 559 & 71.0 \\
\hline
\end{tabular}

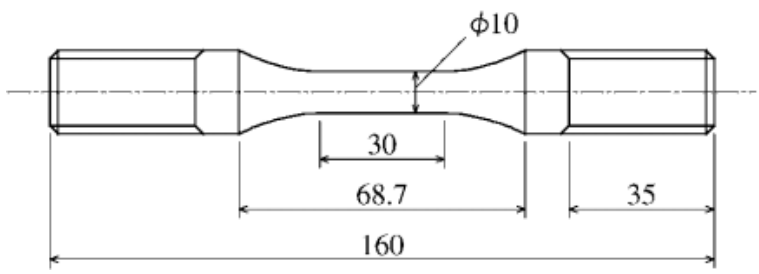

Fig. 1 Configuration of fatigue test specimen.

学成分，溶体化処理条件，母材形状と機械的性質をそれぞれ Table 1 と Table 2 に示す.この材料より Fig. 1 に示す丸棒 試験片を製作し，室温にて以下に示す疲労試験を行なった。 試験片平行部は機械加工後, エメリ紙の 1000 番まで長手方 向に研磨した．疲労試験前の未損傷の試験片を標準試料とし て陽電子寿命測定を行った。

疲労試験は完全引張圧縮荷重制御またはひずみ制御で，室 温大気中にて行なった．荷重制御試験では応力振幅 220 $\mathrm{MPa}$ ，周波数 $1.7 \mathrm{~Hz}$ の正弦波，ひずみ制御試験ではひずみ 振幅 $0.31 \%$, ひずみ速度 $0.4 \% / \mathrm{s}$ の三角波とした．荷重制御 試験打よびひずみ制御試験についてそれぞれ破断まで行な い, 破断繰り返し数 $N_{\mathrm{f}}$ を求めた. 次いで, 繰り返し数を $N$, 疲労寿命比を $N / N_{\mathrm{f}}$ とし，いくつかの $N / N_{\mathrm{f}}$ に相当する 途中止試験片を製作し，中央部を切断して陽電子寿命測定 を行なった。

本研究では, 透過型アバランシェ・ダイオードを用いて新 しく開発された $\beta^{+}-\gamma$ 同時計測陽電子寿命測定法 ${ }^{1)}$ を適用し た．Fig. 2 にその装置のブロック図を示す。陽電子線源は $1.8 \mathrm{MBq}$ の ${ }^{68} \mathrm{Ge}$ 密封線源を用いた。線源から放射された陽 電子はアバランシェ・ダイオードを透過しスタート信号を与 えた後, 試料に入射し試料内で消滅して 2 本の消滅 $\gamma$ 線を 放出する。この消滅 $\gamma$ 線をストップ信号とし，スタート信号 との時間差測定により陽電子寿命スペクトルを得る。本装置 の時間分解能 (Full Width at Half Maximum, FWHM) は約 220 ps という優れたものであった.

本実験で測定された陽電子寿命スペクトルについて RESOLUTION ${ }^{5)}$ あるいは POSITRONFIT5) プログラムで 解析を行ない, 試験片に抢ける平均陽電子寿命值 $\tau_{\mathrm{m}}$ 抢よび 2 成分解析による陽電子寿命值 $\tau$ と相対強度 $I$ を求めた.

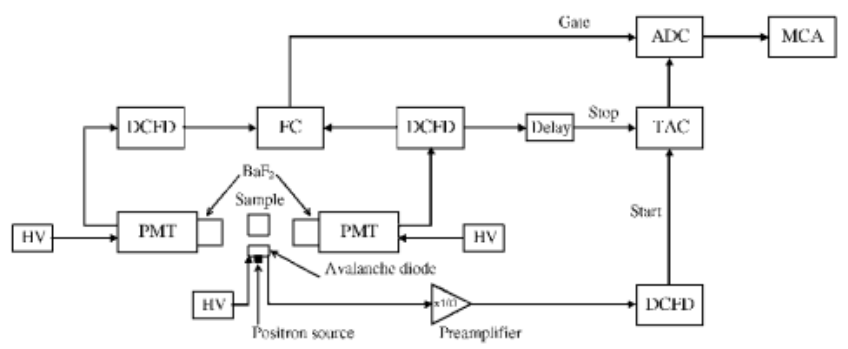

Fig. 2 Block diagram of the $\beta^{+}-\gamma$ coincidence positron lifetime spectrometer. Abbreviations: PMT, photomultiplier tube; $\mathrm{HV}$, high voltage power supply; DCFD, differential constant fraction discriminator; FC, fast coincidence; TAC, time-to-amplitude converter; ADC, analog-to-digital converter; MCA, multichannel analyzer.

\section{3. 実験結果および考察}

本実験で用いられるステンレス鋼 SUS316 の未損傷試験 片標準試料に抢ける陽電子寿命測定を行なった結果, 103 ps の陽電子寿命値が得られた。これは鉄合金に扔ける完全結晶 中の陽電子寿命值であり, 溶体化処理された SUS316 試験 片には転位や空孔などの格子欠陥がほとんどないこと(約 1 ppm 以下)を示している. 透過型電子顕微鏡 (TEM)による ミクロ組織観察に扔いても，転位などの欠陥が少なく，析出 物も観察されなかっだ).

応力振幅 $220 \mathrm{MPa}$ の荷重制御試験抢よびひずみ振幅 $0.31 \%$ のびみ制御試験に打ける繰り返し数 $N$ と平均陽電 子寿命值 $\tau_{\mathrm{m}}$ の関係を Fig. $3(\mathrm{a})$ に, 疲労寿命比 $N / N_{\mathrm{f}}$ と平均 陽電子寿命值 $\tau_{\mathrm{m}}$ の関係を Fig. 3 (b) に示す. 未損傷試験片に 打ける陽電子寿命值もあわせて示した。

荷重制御試験およびひずみ制御試験いずれの場合も繰り返 し数あるいは疲労寿命比の増加に伴い平均陽電子寿命值 $\tau_{\mathrm{m}}$ は単調に増加し, ひずみ制御では荷重制御に比べ, 疲労初期 に扔いて $\tau_{\mathrm{m}}$ は早くから上昇することがわかる。 また $\tau_{\mathrm{m}}$ は， 疲労末期に㧍いて荷重制御とひずみ制御でほぼ同じ值(約 $136 \mathrm{ps）となる.}$

以前に報告されたドップラー幅広がり測定を用いた陽電子 消隇法によるステンレス鋼 SUS316 の疲労損傷過程に抢け る $\mathrm{S}$ パラメータの解析結果 ${ }^{4)}$ と本研究の平均陽電子寿命 $\tau_{\mathrm{m}}$ の解析結果は, 極めてよく似た変化を示し, 疲労寿命比の増 加に伴って単調に増加する。ここで注意すべきことは, ドッ プラー幅広がり測定法の S パラメータは相対変化量で評価 するものであり, 従って疲労の進行度を評価するためには, あらかじめマスターカーブの作成を必要とする。一方，陽電 子寿命測定法の $\tau_{\mathrm{m}}$ は物理量であり, 絶対值そのもので評価 が可能である.ささらに, 次に示すように陽電子寿命スペクト ルの 2 成分解析を行なうことによって, 格子欠陥の種類の 


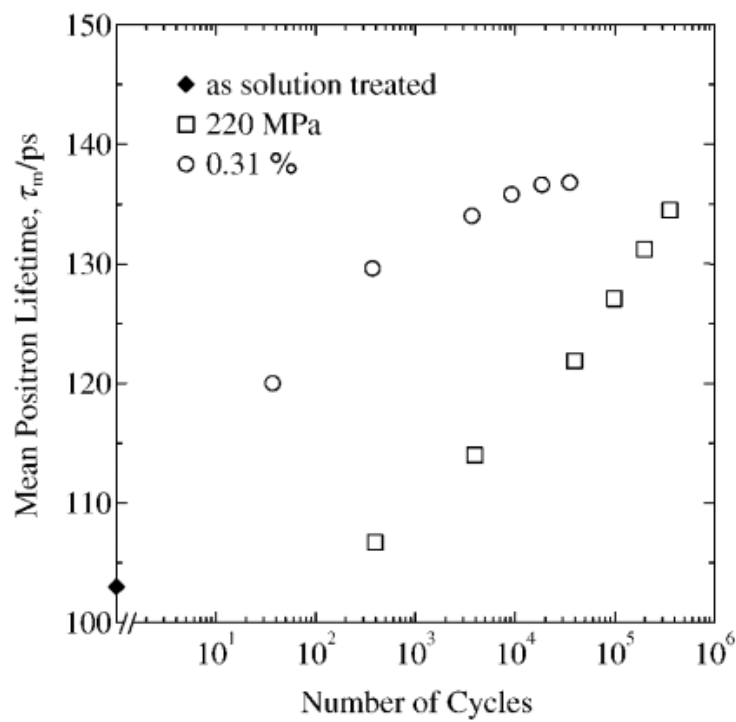

(a) Relationship between number of cycles and mean positron lifetime.

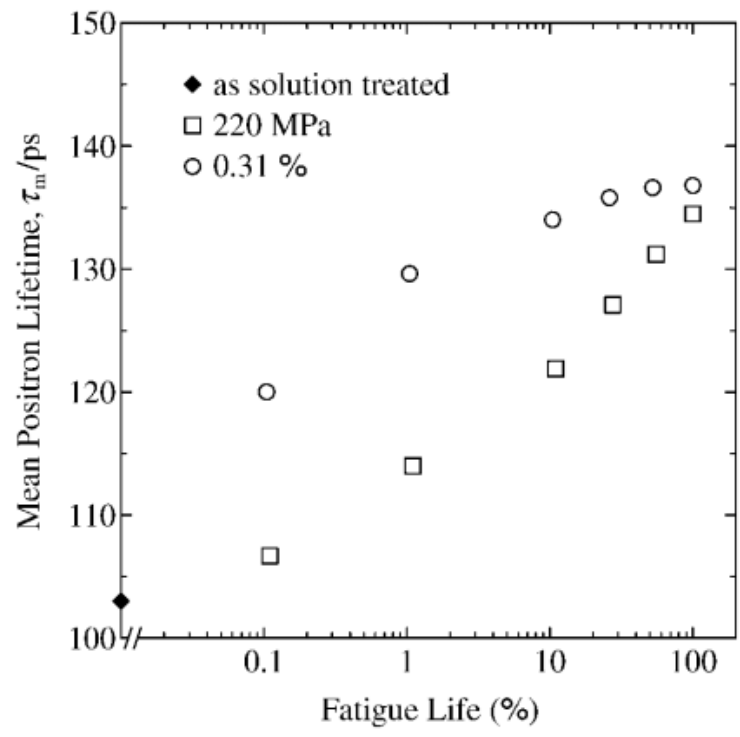

(b) Relationship between fatigue life and mean positron lifetime.

Fig. 3 Results of positron lifetime measurement in stress-controlled fatigue (stress amplitude: $220 \mathrm{MPa}$ ) and strain-controlled fatigue (strain amplitude: $0.31 \%$ ).

同定やその濃度を評価することが可能であり, ドップラー幅 広がり測定法では知り得ない情報も得ることができる。

陽電子寿命スペクトルの 2 成分解析を行なった結果を Fig. 4 に示す. 欠陥成分の陽電子寿命 $\tau_{\mathrm{d}}$ は疲労寿命比によ る変化はほとんどなく，その値は約 150 ps である．欠陥成 分の相対強度 $I_{\mathrm{d}}$ は疲労寿命比に伴い増加し, 疲労初期では ひずみ制御のほうが荷重制御より高い值を示し, 疲労末期で はいずれもほぼ同じ值(約 85\%)を示す.

欠陥成分の陽電子寿命 $150 \mathrm{ps}$ は，鉄の冷間圧延において も同じ寿命值が観測され ${ }^{6)}$ ，鉄中の単空孔に打ける寿命 $(175$ $\left.\mathrm{ps}^{7)}\right)$ より短いことから，転位での寿命であると考えられ る. その相対強度 $I_{\mathrm{d}}$ は転位密度に対応する. Fig. 4 の結果 は，荷重制御試験およびひずみ制御試験いずれの場合におい
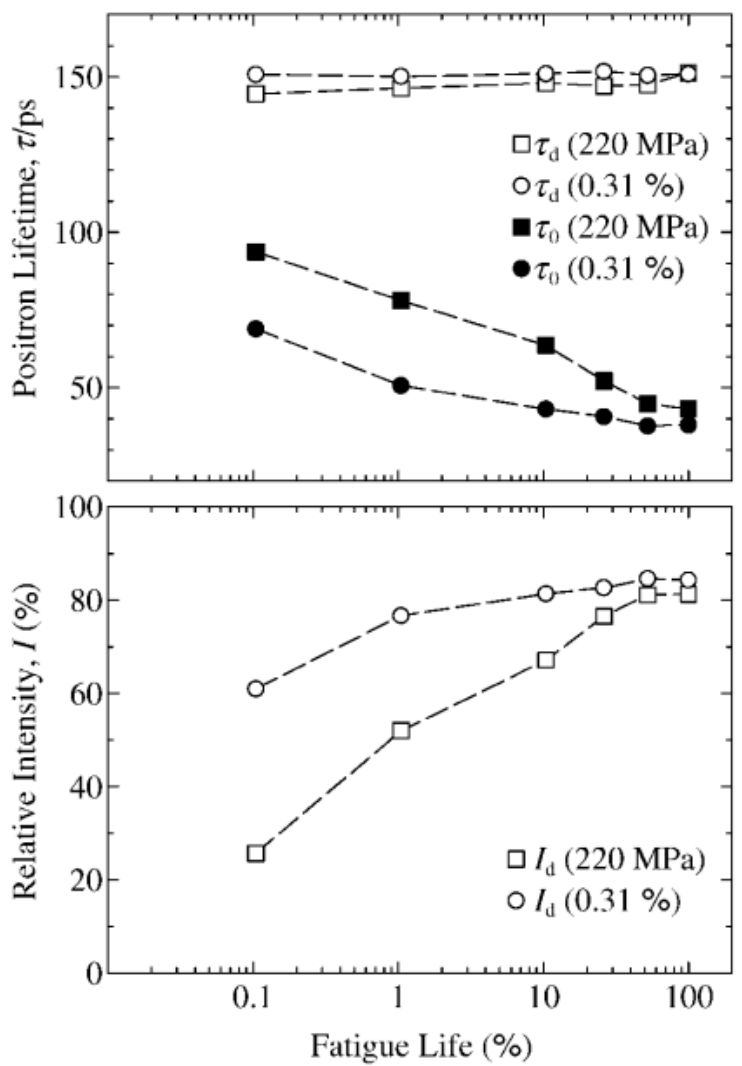

Fig. 4 Results of two-component positron-lifetime analysis in stress-controlled fatigue (stress amplitude: $220 \mathrm{MPa}$ ) and strain-controlled fatigue (strain amplitude: 0.31\%).

ても，疲労の蓄積に伴い転位密度が増加していき，疲労限に 達するときにはほぼ同じ転位密度になっていることを示して いる．荷重制御に比べひずみ制御のほうは疲労の初期から転 位密度が高く，疲労初期に拈ける損傷が大きいことがわかる.

TEM による観察に扔いても同様の観察結果が得られた とから明らかなように，疲労損傷度の非破壊的評価方法とし て陽電子寿命測定法は極めて有効と考えられる.

本研究で初めて新しい $\beta^{+}-\gamma$ 同時計測陽電子寿命測定装置 を適用し，ステンレス鋼 SUS316 の疲労損傷度を精度よく 評価できることが明らかとなった。銅単結晶の疲労試験に $\beta^{+}-\gamma$ 同時計測陽電子寿命測定法を適用した例は過去にも報 告されている8)が，陽電子の検出にプラスチック・シンチ レータを用いているため, その検出効率が非常に悪く, 装置 分解能(FWHM) が約 $280 \mathrm{ps}$ で，本装置の性能と比べてかな り劣っている.

本実験で用いた陽電子寿命測定装置は, 従来の $\beta^{+}-\gamma$ 装置 と同様に試料位置に消隇 $\gamma$ 線の検出器 2 本を対向させて設 置しなければならないため，実際に原子力発電所内の配管等 の疲労損傷を現場測定することは困難である。また，装置の 計浿器システムもいくつもの精密電子計測機器を組み合わせ たものから成っているため, 様々な現場までの運搬には不向 きである. 非破壊検查器として実用化するためにはこれらの 問題点を解決する必要があり，その方法として陽電子検出扔 よび 2 本の消滅 $\gamma$ 線検出を含めた検出部の改良, 計測器シ ステムの簡略化・小型化などが挙げられる. 現在，これらの 改良を加えたコンパクトな可搬型 $\beta^{+}-\gamma$ 同時計測陽電子寿命 
測定非破壊検査器の開発に着手している.

\section{4. 結言}

新しい $\beta^{+}-\gamma$ 同時計測陽電子寿命法を用いて，ステンレス 鋼 SUS316 の疲労損傷度を非破壊的に精度よく評価できる ことが明らかとなった．陽電子寿命測定により材料の余寿命 が予測でき，さらにその成分解析により欠陥種と量の情報も 得られ, 疲労による蓄積損傷をより詳細に評価することがで きることが示された．現在，この測定法を利用した可搬型 $\beta^{+}-\gamma$ 同時計測陽電子寿命測定非破壊検査器を開発中で, 近 い将来現場で実際に利用できるものと期待される.

本研究は文部科学省科学研究費補助金の研究助成によるも のであり，ここに記して感謝の意を表します。また，本研究 の一部は科学技術振興調整費充当戦略的研究拠点阪大フロン ティア研究機構において実施したことを付記し, 謝意を表し ます。

\section{文献}

1) P. Chalermkarnnon, M. Yuga, S. Nakata, S. Kishimoto, H. Araki and Y. Shirai: Radioisotopes $\mathbf{5 0}$ (2001) 576-580.

2) P. J. Hautojärvi ed.: Positrons in Solids, (Springer-Verlag, Berlin, 1979).

3) JRIA ed.: Youdenshi Keisoku no Kagaku, (Maruzen, Tokyo, 1993).

4) Y. Kawaguchi and N. Nakamura: J. Japan Inst. Metals 65(2001) 835-842.

5) P. Kirkegaard, N. J. Pedersen and M. Eldrup: PATFIT-88: A Data-Processing System for Positron Annihilation Spectra on Mainframe and Personal Computers. RISO-M-2740, (Riso National Laboratory, Denmark, 1989).

6) C. Hidalgo, G. González-Doncel, S. Linderoth and J. San Juan: Phys. Rev. B 45(1992) 7017-7021.

7) A. Vehanen, P. Hautojärvi, J. Johansson, J. Yli-Kauppila and P. Moser: Phys. Rev. B 25(1982) 762-780.

8) S. Hansen, U. Holzwarth, M. Tongbhoyai, T. Wider and K. Maier: Appl. Phys. A 65 (1997) 47-52. 